www.jmscr.igmpublication.org

Impact Factor 5.84

Index Copernicus Value: 71.58

ISSN (e)-2347-176x ISSN (p) 2455-0450

crossref DOI: _https://dx.doi.org/10.18535/jmscr/v5i9.123

Journal Of Medical Science And Clinical Research

\title{
Immediate Implant Placement with Immediate Loading in Esthetic Zone after Determination of Bone Width Available in Fresh Extraction Site: A Case Report
}

\author{
Authors \\ Dr Harshad Wagaj ${ }^{1}$, Dr Asha Jare Wagaj ${ }^{2}$, Dr Shubha Rao ${ }^{3}$, \\ Dr Akash Lavate ${ }^{4}$, Dr Kaustubh Tambekar ${ }^{5}$, Dr Shirish Aghav ${ }^{6}$, Dr Pravin Gaikwad ${ }^{7}$ \\ ${ }^{1}$ Assistant Prof, Dept of Prosthodontics, Pandit Deendayal Upadhay Dental College, Solapur, India \\ Email: drharshad.wagaj@gmail.com \\ ${ }^{2} 2^{\text {nd }}$ year PG student, Dept of Orthodontics, Pandit Deendayal Upadhay Dental, College, Solapur, India \\ ${ }^{3}$ Private Practitioner, India \\ ${ }^{4}$ Reader, Dept of Orthodontics, Pandit Deendayal Upadhay Dental College, Solapur, India \\ Email:akashortho@yahoo.com \\ ${ }^{5}$ Reader, Dept of Oral and maxillofacial surgery, Pandit Deendayal Upadhay Dental College, Solapur, India \\ ${ }^{6,7}$ Private Practitioner, Prosthodontist, India
}

\begin{abstract}
Aim: Immediate implant placement with immediate loading in esthetic zone after determination of bone width available in fresh extraction site.

Procedure: Pre-extraction ridge mapping and upper arch impression using putty rubber base impression material is made, followed by atraumatic tooth extraction; extracted tooth is cleaned, disinfected and reoriented in the earlier made impression. The cast obtained is used to measure bone width. Then implant size is decided and placement was done and abutment milled in laboratory, temporisation immediately given.
\end{abstract}

Conclusion: This technique will help the surgeon to understand the thickness of labial plate especially the apical region without reflecting the flap, also aids in selection of proper dimension of dental implant, and if bone graft is needed.

Keywords: Dental implants, ridge mapping, immediate implant, immediate loading.

\section{Introduction}

Smile is an everlasting embellishment. Extracting any tooth can be a traumatic experience for a patient especially when the tooth is from esthetic zone. A dental implant can be placed immediately after extraction. ${ }^{2,3}$ Brånemark and co-worker documented a healing period of 6-12 months between tooth extraction and implant placement.
As a result of continued research, a number of the concepts such as delayed implant placement, delayed loading etc.; have been revised and improved. ${ }^{2}$ Success of dental implant is not only defined by osseointegration of the implant, but a harmonious and natural blending of the restoration with the surrounding tissues and dentition. Biological, functional, and biomechanical 
parameters must be examined, and potential problems have to be identified preoperatively. Such influencing factors are the amount of available alveolar bone, morphologic type of the soft tissue; correct positioning of the implant in all three dimensions, the provisional phase, the design and material of the implant abutment, and material and design of the definitive crown. ${ }^{1,7,8}$

Successful implant treatment planning includes radiographic and clinical examination that provides information about location of anatomical structure, quality and quantity of bone, presence of any lesion, occlusal pattern, number and size of implant as well as prosthesis design. In radiographic imaging panoramic, intraoral periapical, computer tomography and cone beam computer tomography (CBCT) are recommended. Panoramic and intraoral periapical views are hampered by image distortion and inability to provide buccolingual cross section ${ }^{8}$. The use conventional computer tomography $(\mathrm{CT})$ provides ability to assess the quantity and quality of bone and critical anatomic structures. But the disadvantages are the length of time to produce an image (20-25 $\mathrm{min}$ ), the cumulative radiation dose to the head and neck area and the possibility of a distorted image with metallic tooth restorations and/ or patient movement ${ }^{9,10}$. A consideration with CBCT imaging is financial cost. ${ }^{1,8}$ To overcome conventional radiographic limitations, clinical methods suggested by Wilson (1989) and Traxler (1992) is ridge mapping provides alveolar ridge dimensions. But the ridge mapping does not provide the width of individual facial and palatal cortical plates over the roots. To overcome all this limitations, a simplified method is described in following case to determine amount of bone labially and palatally and immediately placing implant with immediate restoration.

\section{Case Report}

A 24 years old male patient came to Department of Prosthodontics, crown and bridge at P.D.U. Dental college and research center, Solapur with dislodged prosthesis in relation with upper right central incisor [figure 1]. Patient had history of root canal treatment and crown prosthesis in relation with 11 . The intraoral periapical radiograph revealed the radiopacity suggestive of post and core treated fractured tooth with periapical periodontal widening. After discussing all advantages, disadvantages of treatment plan, the consent from patient taken.

In first visit impression was made with irreversible hydrocolloid (Imprint, DPI, India) and a diagnostic cast was poured with type III dental stone (Kalabhai Dental, India). A stent is prepared using a vacuum-adapted thermoplastic sheet on cast. A series of calibrated holes every $2 \mathrm{~mm}$ were made on the labial and palatal region of the stent covering the crown and tooth to be extracted. Following administration of local anaesthetic agent, the stent was located in patient's mouth and ridge mapping procedure carried with number 20 endodontic file for the measurement of thickness of the mucosa covering the bone. An accurate impression of the maxillary arch using an addition silicone putty impression material was using an appropriate stock tray.

Patient was advised to start with an antibiotic coverage (combination of Amoxicillin 500mg and Clavulanic acid $125 \mathrm{mg}$ ) one day prior to the surgery. After maintaining aseptic condition and following surgical protocol, local anaesthesia administered and atraumatic tooth extraction was done. Care has to be taken not to fracture the tooth as well as labial bone plate while extraction. The socket was debrided with bone curette. The surgical site was protected by giving saline soaked gauze pack. Extracted crown with root stump tooth to be cleaned, disinfected and reoriented in the earlier made impression [figure 2] and poured the impression in a type III dental stone. The cast is sectioned in a centre along the long axis of the extracted crown $\mathrm{n}$ root stump. Transfer the ridge mapping reading recorded earlier clinically to the sectioned cast [figure 3]. Scrap the cast in the labial and palatal region as per the transferred ridge mapping reading to eliminate the soft tissue covering the bone. As a result of the scrapping of 


\section{JMSCR Vol||05||Issue||09||Page 28110-28114||September}

the working cast, the exact amount of labial and palatal plate bone width can be measured with the help of vernier calliper.

Then proper dimension of implant was selected. Care should be taken to place the implant as apically (at least 3 to $5 \mathrm{~mm}$ ) and palatally as possible to get primary stability and submerged at least 1.5 to $2 \mathrm{~mm}$ considering horizontal bone loss of 1 to $1.5 \mathrm{~mm}$ initially in one year [figure 4]. The jumping distance was filled with composite graft. Abutment was milled extraorally and checked in patient mouth then screw is placed in position with torque wrench near about $20 \mathrm{~N}$ torque. The screw access hole was closed with putty material and temporisation was made with the help of composite restorative material. Care should be taken that temporary crown is not given in contact with lower anterior and anterior guidance is established on adjacent central incisor. The crown is cemented with temporary luting cement [figure 5]. Finally self resorbable suture was placed.

After healing period of 6 months, open tray impression was made with addition silicone impression material and zirconia abutment [figure 6] with lithium disilicate crown fabricated [figure 7].

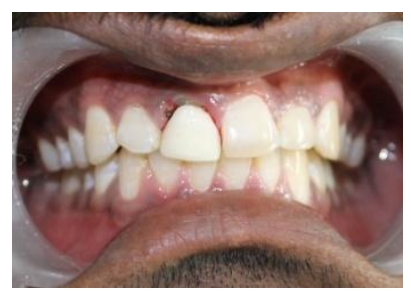

Fig.1 Preoperative intraoral view with dislodged prosthesis with right central incisor.

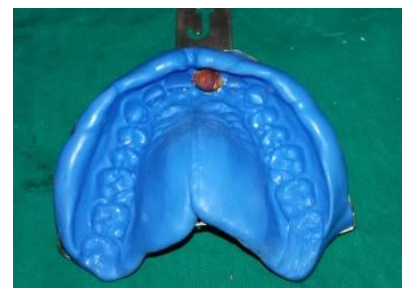

Fig. 2 Cleaned extracted tooth, reoriented in the earlier recorded elastomeric putty impression.

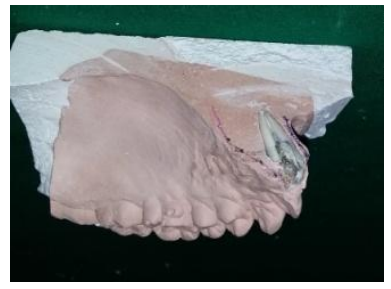

Fig 3 Transfer of ridge mapping reading to sectioned cast.

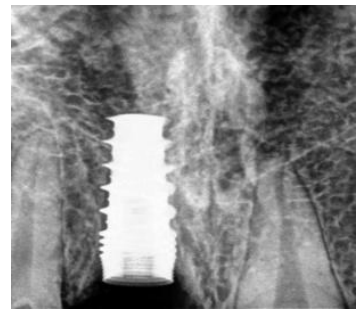

Fig.4 Submerged implant seen in IOPA.

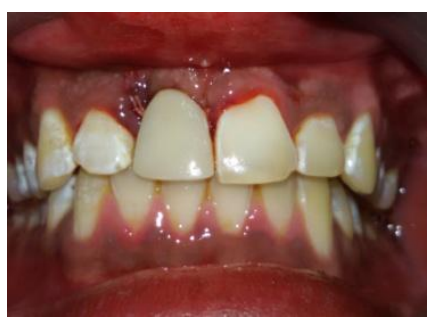

Fig.5 Immediately loading done with composite crown (Temporisation).

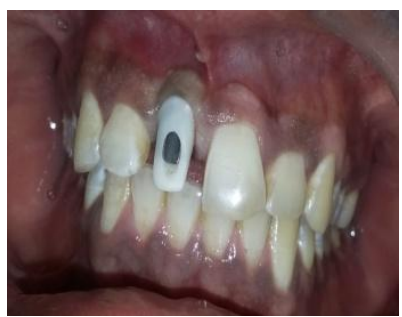

Fig.6 Zirconia abutment in situ.

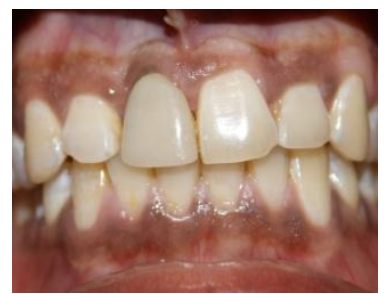

Fig.7 Lithium disilicate crown with proper emergence profile

\section{Discussion}

In all phases of clinical dentistry careful planning and diagnosis results in predictable outcome. Immediate placement of implant with immediate loading of restoration is esthetically and function- 
nally depends on meticulous planning and careful surgical procedure. Measurement of labial as well as palatal bone width with help of ridge mapping and transferring records to sectioned cast is a predictable method to determine bone width available in fresh extraction socket and it should be preferred over another diagnostic method.

There are certain advantages of this method combining with immediate implant placement with immediate loading are, shortening in treatment time, psychological stress is avoided by suppressing need for repeat surgery, post extraction alveolar bone resorption is reduced, preserves the morphology of soft tissue around peri- implant, allows precise implant placement and improves the prosthetic emergence profile.

The only limitation is that, this procedure is to be carried out immediately after the extraction; additional chair side time is needed prior to surgery.

\section{Conclusion}

This case results, immediate implant with immediate loading after determination of bone width available in fresh extraction socket is predictable treatment. This technique will help the surgeon to understand

1) The thickness of labial plate especially the apical region without reflecting the flap.

2) Whether the bone graft and membrane is needed; can be judged before surgery.

3) The dimension of the implant to be placed can be determined before surgery.

4) And can be used in root stem, fractured tooth, avulsed tooth condition wherein immediate implantation is planned.

\section{References}

1. Technique to assess the alveolar bone width for immediate implant placement in fresh extraction sockets. Neeraj Kumar Chandraker, Ramesh Chowdhary, Abha Verma Indian Journal of Dental Research, 24(6), 2013
2. Implants into fresh extraction site: A literature review,case immediate placement report Abu-Hussein Muhamad1,2, Abdulghani Azzaldeen3, Sarafi Anou Aspasia4, Kontoes Nikos5 Journal of Dental Implants | Jul - Dec 2013 | Vol 3 | Issue 2

3. Comparative evaluation of three different methods for evaluating alveolar ridge dimension prior to implant placement: An in vivo study Anshul Chugh, Poonam Bhisnoi, Divya Kalra, Sarita Maggu, Virendera Singh : Journal of Dental Implants | Jul - Dec 2013 | Vol 3 | Issue 2

4. Dental Extraction,Immediate Placement of Dental Implants, and Immediate Function Ole T. Jensen, DDS, MS Oral Maxillofacial Surg Clin N Am 27 (2015) 273-282

5. Brånemark PI, Adell R, Breine U, Hansson BO, Lindström J, Ohlsson A. Intra-osseous anchorage of dental prostheses. I. Experimental studies. Scand J Plast Reconstr Surg 1969;3:81-100.

6. Sclar AG. Strategies for management of single-tooth extraction sites in aesthetic implant therapy. J Oral Maxillofac Surg 2004;62(9 Suppl 2):90-105.

7. Belser UC, Schmid B, Higginbottom F, Buser D. Outcome analysis of implant restorations located in the anterior maxilla: A review of the recent literature. Int J Oral Maxillofac Implants 2004;19(Suppl):3042.

8. Allen F, Smith DG. An assessment of the accuracy of ridge-mapping in planning implant therapy for the anterior maxilla. Clin Oral Impl Res 2000:11:34-8.

9. Kassebaum DK, Nummikoski PV, Triplett RG, Langlais RP. Cross sectional radiography for implant site assessment. Oral Surg Oral Med Oral Pathol 1990;70:674-8.

10. Schwarz M, Rothman SL, Rhodes ML, Chafetz N. Computed tomography: Part II. Preoperative assessments of the maxilla 
for endosseous implant surgery. Int J Oral Maxillofac Implants 1987;2:143-8.

11. Wilson, DJ. Ridge mapping for determination of alveolar ridge width.Int $\mathbf{J}$

Oral Maxillofac Implants 1989;4:41-3. 